\title{
Advanced oxidation protein products from the follicular microenvironment and their role in infertile women with endometriosis
}

\author{
YALI SONG ${ }^{1 *}$, JING LIU $^{1 *}$, ZHUOLIN QIU ${ }^{1}$, DONGHONG CHEN ${ }^{1}$, CHEN LUO $^{1}$, XIAONING LIU $^{2}$, \\ RUI HUA ${ }^{1}$, XI ZHU ${ }^{1}$, YANLING LIN ${ }^{3}$, LINA LI ${ }^{1}$, WENLIAN LIU ${ }^{1}$ and SONG QUAN ${ }^{1}$ \\ ${ }^{1}$ Center for Reproductive Medicine, Department of Obstetrics and Gynecology, Nanfang Hospital, Southern Medical University, \\ Guangzhou, Guangdong 510515; ${ }^{2}$ Center for Reproductive Medicine, Department of Obstetrics and Gynecology, \\ Hengsheng Hospital, Southern Medical University, Shenzhen, Guangdong 510888; ${ }^{3}$ Clinical Medicine, \\ Southern Medical University, Guangzhou, Guangdong 510515, P.R. China
}

Received June 5, 2017; Accepted September 7, 2017

DOI: $10.3892 /$ etm.2017.5390

\begin{abstract}
Endometriosis (EM) is associated with oxidative stress. Advanced oxidation protein products (AOPPs) are novel markers of oxidative stress, which serve an important role as an inflammatory mediator in various chronic diseases. In order to examine the role of AOPPs in infertile women with EM, the present study analyzed the levels of AOPPs, estradiol $\left(\mathrm{E}_{2}\right)$ and progesterone $\left(\mathrm{P}_{4}\right)$ in the follicular fluid (FF) of 89 women with or without EM undergoing in vitro fertilization (IVF). The AOPP concentration in the FF of the EM group was significantly higher when compared with that of the control group (51.5 \pm 22.4 vs. $41.8 \pm 18.3 \mu \mathrm{mol} / \mathrm{l} ; \mathrm{P}<0.05)$. However, the FF $\mathrm{P}_{4}$ levels and blastocyst rate were significantly lower in the EM group compared with the control group $\left(\mathrm{P}_{4}: 1,249.6 \pm 465.4\right.$ vs. $1,752.7 \pm 565.4 \mathrm{ng} / \mathrm{ml}, \mathrm{P}<0.05$; blastocyst rate: $0.511 \pm 0.322$ vs. $0.662 \pm 0.278 ; \mathrm{P}<0.05)$. The AOPP concentration and $\mathrm{P}_{4}$ level in the FF presented a significant negative correlation in the EM and control groups, as well as in the total cohort of patients (EM group: $\mathrm{r}=-0.406, \mathrm{P}=0.006$; control group:
\end{abstract}

Correspondence to: Dr Song Quan, Center for Reproductive Medicine, Department of Obstetrics and Gynecology, Nanfang Hospital, Southern Medical University, 1838 Guangzhou Avenue North, Guangzhou, Guangdong 510515, P.R. China

E-mail: quangsong3@126.com

*Contributed equally

Abbreviations: AOPPs, advanced oxidation protein products; EM, endometriosis; $\mathrm{E}_{2}$, estradiol; $\mathrm{P}_{4}$, progesterone; $\mathrm{FF}$, follicular fluid; IVF, in vitro fertilization; ROS, reactive oxygen species; LH, luteinizing hormone; hCG, human chorionic gonadotropin; ART, assisted reproductive technology

Key words: advanced oxidation protein products, follicular fluid, hormones, in vitro fertilization, endometriosis $\mathrm{r}=-0.315, \mathrm{P}=0.035$; total: $\mathrm{r}=-0.421, \mathrm{P}<0.001)$. In addition, there was a significant negative correlation between the FF AOPP concentrations and blastocyst rate in the EM group and in the total cohort (EM group: $\mathrm{r}=-0.376, \mathrm{P}=0.012$; total: $\mathrm{r}=-0.367$, $\mathrm{P}<0.001)$. In conclusion, these results suggested that AOPPs may be a potentially effective marker for predicting the oocyte quality and outcomes of IVF in infertile women with EM.

\section{Introduction}

Oxidative stress results from a disruption of the balance between the pro-oxidation and anti-oxidation systems. The physiological level of reactive oxygen species (ROS) serves an important role in female reproduction, including in ovarian steroidogenesis, oocyte maturation, folliculogenesis, ovulation and luteolysis $(1,2)$. Production of physiological levels of oxygen radicals at ovulation in response to luteinizing hormone (LH) may signal differentiation of the oocyte. However, overproduction may damage the oocytes and mitochondrial membrane potential, reduce the mitochondrial DNA copy number and disrupt the mitochondrial metabolism; all these changes are observed in atresia. Subsequently, the lack of adenosine triphosphate causes severe damage to the ultrastructure of mitochondrial cristae and spindle formation in oocytes $(3,4)$.

Endometriosis (EM) is an estrogen-dependent disease characterized by the presence and growth of endometrial tissue outside the uterine cavity (5). EM is strongly associated with infertility, and has severe effects on ovarian and tubal function, while it may also affect endometrial receptivity (6-11). The development of in vitro fertilization (IVF) is promising for infertile patients with EM; however, the success rate of this procedure remains at a low level (12). One of the main causes of failure may be the poor quality of oocytes (13). Thus, research has been focusing on determining the causes of poor oocyte quality in infertile women with EM and improving their quality.

In recent years, the correlation between oxidative stress and EM has received increasing attention. EM is considered to be associated with oxidative stress, and several studies have 
demonstrated that the follicular fluid (FF) of patients with EM presented increased levels of ROS and a reduction in the total antioxidant capacity (14-16). In addition, the FF of infertile women with mild EM was demonstrated to greatly impair the meiotic spindle of bovine oocytes matured in vitro (17). It has also been observed that decreased percentage of mature oocytes, implantation rate and clinical pregnancy rate were associated with the severity of EM (18). Furthermore, the level of myeloperoxidase as a potential oxidative stress target was revealed to be an indicator of EM-associated infertility (18). The findings of these previous studies suggest that the poor oocytes quality for EM may be associated with oxidative stress.

Advanced oxidation protein products (AOPPs) are a marker of oxidation-mediated protein damage that are usually carried by plasma proteins (19). AOPPs induce an oxidation stress reaction in vivo by activating the neutrophil and monocyte oxidative metabolism (20), and circulate for prolonged periods in the patients' blood, since their degradation by cells requires several hours or days since their degradation by cells requires several hours or days (21). Due to the sensitivity, stability, convenience and cost of detection, the role of AOPPs in predicting the severity of oxidative stress and disease prognosis has become increasingly important. AOPPs may accelerate renal fibrosis and atherosclerosis, and may be detrimental to the progression of chronic kidney disease (22-24). In postmenopausal women, AOPPs are negatively associated with a reduced bone mineral density, which increases an individual's risk of developing osteoporosis (25). As a key product in oxidative reactions, AOPPs and their effects on the female reproductive system have received increasing attention. It has been demonstrated that the levels of serum AOPPs are significantly increased in women with polycystic ovarian syndrome (26). In patients with uterine leiomyoma, the serum level of AOPPs increases and the antioxidant capacity decreases (27). In the peritoneal fluid, the level of AOPPs is significantly higher in patients with EM when compared with that in patients without EM (21). However, to the best of our knowledge, there are no previous studies on AOPP levels in the FF of infertile women with EM undergoing IVF.

The FF arises from the secretion of theca and granulosa cells, and forms a direct microenvironment for the development of oocytes, having crucial effects on the oocyte quality (28). Estradiol $\left(\mathrm{E}_{2}\right)$ and progesterone $\left(\mathrm{P}_{4}\right)$ in the $\mathrm{FF}$ are closely associated with the quality of oocytes. In our previous study, a high level of AOPPs in the FF resulted in adverse effects on oocytes and early embryonic development, while it was negatively associated with the outcome of IVF (29).

In the present study, the aim was to examine the role of AOPPs in infertile women with EM undergoing IVF and whether they are involved in altering the follicular environment of the developing oocyte, subsequently affecting the outcome of IVF. The levels of AOPPs, $\mathrm{E}_{2}$ and $\mathrm{P}_{4}$ in the FF were detected, and the correlations between gonadal hormones levels, prognosis of IVF and AOPP concentration were analyzed.

\section{Materials and methods}

Patients and sample collection. A total of 89 infertile women (age, 20-40 years) were recruited between 01 April 2015 and
31 December 2016. All patients were undergoing IVF at the Center for Reproductive Medicine, Department of Obstetrics and Gynecology, Nanfang Hospital, Southern Medical University (Guangzhou, China). Among the 89 women, 44 were diagnosed with EM (stages II, III and IV) that was confirmed by laparoscopy and biopsy, while 45 non-EM women because of male factors were enrolled into the control group. For the patients with EM, the date of surgical diagnosis was within 1-4 years, and the minimum period between the last surgery and IVF was at least 6 months. Women in the control group were considered to have no significant infertility factors according to the World Health Organization guidelines (30). All women included in the present study did not receive any medicinal treatment other than the necessary treatment stipulated in the IVF protocol during the past 3 months. IVF stimulation protocols were compliant to the standard treatment dictated by the patients' physicians.

Subsequent to obtaining informed consent from the participants, FF samples were collected on the retrieval day (day of transvaginal oocyte retrieval) from patients undergoing IVF. Biochemical measurement of AOPP concentration was performed in all samples. The outcome of the research did not affect the treatment of participants. In addition, all the information collected in the present study does not identify individual participants. The approval of the study was obtained from the Institutional Research Ethics Board of Nanfang Hospital of Southern Medical University (Guangdong, China).

Oocyte evaluation. Oocyte maturity was examined by embryologists subsequent to transvaginal oocyte retrieval or at the time of intracytoplasmic sperm injection. The evaluation for oocytes was performed according in the following parameters: Expanded cumulus, appropriate cytoplasmic maturation, extruded first polar body and arrest in metaphase II. The embryo quality was scored at day 3 following fertilization and prior to placement in the uterus, as follows: Grade I, very good quality; grade II, good quality; grade III, medium quality; and grade IV, poor embryo quality (13). A good embryo (grades I and II) was defined as having seven or eight blastomeres, which were equally sized, with $<20 \%$ fragmentation and no multinucleation.

IVF-controlled ovarian hyperstimulation protocol. Stimulation protocols were personalized, and included a leuprolide acetate long protocol and a gonadotropin-releasing hormone antagonist protocol (17). Controlled ovarian stimulation was performed by administering recombinant follicle-stimulating hormone (Gonal-F; EMD Serono, Inc., Rockland, MA, USA; or Puregon; MSD, Kenilworth, NJ, USA). Ovulation was induced with $250 \mu \mathrm{g}$ recombinant human chorionic gonadotropin (Ovidrel, EMD Serono, Inc.) subcutaneously or 6,000-10,000 U human chorionic gonadotropin (hCG; Chorionic Gonadotropin for injection; Livzon Pharmaceutical Group Inc., Zhuhai, China) intramuscularly at the appropriate time in follicular development. At 34-36 h after hCG administration, transvaginal oocyte retrieval was performed in patients under intravenous sedation.

Collection of the FF. The FF was collected from 89 infertile women, 44 with EM and 45 non-EM with male infertility. At 
Table I. Clinical characteristics and in vitro fertilization outcome parameters in each group.

\begin{tabular}{|c|c|c|c|}
\hline Parameters & EM group $(n=44)$ & Control group $(n=45)$ & P-value \\
\hline Age (years) & $31.3 \pm 4.0$ & $30.6 \pm 3.3$ & 0.542 \\
\hline BMI $\left(\mathrm{kg} / \mathrm{m}^{2}\right)$ & $21.9 \pm 2.9$ & $21.2 \pm 2.2$ & 0.275 \\
\hline Duration of infertility (years) & $3.7 \pm 2.3$ & $3.6 \pm 2.1$ & 0.980 \\
\hline \multicolumn{4}{|l|}{ FF content } \\
\hline AOPP level $(\mu \mathrm{mol} / \mathrm{l})$ & $51.5 \pm 22.4$ & $41.8 \pm 18.3$ & $0.044^{\mathrm{a}}$ \\
\hline $\mathrm{E}_{2}$ level $(\mathrm{ng} / \mathrm{ml})$ & $14.3 \pm 5.9$ & $15.4 \pm 4.8$ & 0.112 \\
\hline $\mathrm{P}_{4}$ level $(\mathrm{ng} / \mathrm{ml})^{\mathrm{b}}$ & $1,249.6 \pm 465.4$ & $1,752.7 \pm 565.4$ & $<0.001^{\mathrm{b}}$ \\
\hline \multicolumn{4}{|l|}{ Prior to hCG administration } \\
\hline LH level $(\mathrm{mU} / \mathrm{ml})$ & $2.2 \pm 2.0$ & $2.1 \pm 1.5$ & 0.098 \\
\hline $\mathrm{E}_{2}$ level $(\mathrm{pg} / \mathrm{ml})$ & $2,471.9 \pm 1333.8$ & $2,903.8 \pm 1255.5$ & 0.064 \\
\hline $\mathrm{P}_{4}$ level (ng/ml) & $0.90 \pm 0.37$ & $0.89 \pm 0.32$ & 0.605 \\
\hline No. of follicles (diameter, $>14 \mathrm{~mm}$ ) & $9.4 \pm 4.9$ & $11.5 \pm 5.2$ & $0.032^{\mathrm{a}}$ \\
\hline No. of fertilizations & $6.3 \pm 3.9$ & $7.9 \pm 3.9$ & $0.024^{\mathrm{a}}$ \\
\hline No. of good embryos & $2.5 \pm 1.8$ & $3.7 \pm 2.3$ & $0.006^{\mathrm{b}}$ \\
\hline Good embryo rate (\%) & $39.0 \pm 19.9$ & $47.3 \pm 19.0$ & 0.061 \\
\hline Blastocyst rate $(\%)$ & $51.1 \pm 32.2$ & $66.2 \pm 27.8$ & $0.022^{\mathrm{a}}$ \\
\hline
\end{tabular}

${ }^{\mathrm{a}} \mathrm{P}<0.05$ and ${ }^{\mathrm{b}} \mathrm{P}<0.01$ indicate a significant difference between the groups. Values are presented as the mean \pm standard deviation. EM, endometriosis; BMI, body mass index; FF, follicular fluid; AOPP, advanced oxidation protein product; $\mathrm{E}_{2}$, estradiol; $\mathrm{P}_{4}$, progesterone; hCG, human chorionic gonadotropin; LH, luteinizing hormone.

the time of oocyte retrieval, the FF was carefully aspirated from the follicle and stored in sterile containers preheated to $37^{\circ} \mathrm{C}$. The FF sample was collected only from a follicle that was $>14 \mathrm{~mm}$ in diameter and first punctured. The preparation of FF was conducted as described by Giorgi et al (31). Subsequently, the oocytes were microscopically removed from the aspirated FF. Only FF samples with no blood contamination upon visual inspection and presenting a mature oocyte were used. FF samples containing $>1$ oocyte or from follicles with a diameter of $<14 \mathrm{~mm}$ were excluded. All FF samples included in the present study were centrifuged at 1,500 $\mathrm{x}$ g for $10 \mathrm{~min}$ at $4^{\circ} \mathrm{C}$ to remove the cellular components, and the clear supernate was stored at $-80^{\circ} \mathrm{C}$ for later analysis.

Measurements of the levels of AOPPs, $E_{2}$ and $P_{4}$. The AOPP concentration in the FF samples was determined according to the spectrophotometric method described by Witko-Sarsat et al (32), which was expressed in equivalents of chloramine-T. Furthermore, the levels of $\mathrm{E}_{2}$ and $\mathrm{P}_{4}$ in the FF were determined using a commercial Iodine $\left({ }^{125} \mathrm{I}\right)$ Radioimmunoassay kit (Beijing North Institute of Biological Technology, Beijing, China), according to the manufacturer's protocol. The assays were assessed using competitive radioimmunoassay. The standard curve and assay sensitivity for $\mathrm{E}_{2}$ was 5-4,000 and $2 \mathrm{pg} / \mathrm{ml}$, respectively, while these values for $\mathrm{P}_{4}$ were $0.2-100$ and $0.2 \mathrm{ng} / \mathrm{ml}$, respectively. For both $\mathrm{E}_{2}$ and $\mathrm{P}_{4}$, the intravariabilities were $<10 \%$ and the interassay variabilities were $<15 \%$.

Statistical analysis. The fertilization rate was defined as follows: Number of embryos/number of oocytes. The good embryo rate was defined as follows: Number of grade I or grade II embryos/total number of embryos. The blastocyst rate as defined as follows: Number of embryos which were applied to culture blastocysts/number of mature blastocysts. All values are presented as the mean \pm standard deviation. Considering the non-Gaussian distribution of the parameters, statistical analysis between groups was performed with the Mann-Whitney U test. Spearman's rank correlation test was applied to analyze the correlations between the FF AOPP concentration and the levels of hormones, correlations between the FF AOPP concentration and the outcome parameters of IVF. A statistically significant difference was defined as $\mathrm{P}<0.05$. Bar graphs were used to present differences between groups. Data were analyzed by SPSS version 20.0 software (IBM Corp., Armonk, NY, USA).

\section{Results}

Clinical characteristics, biochemical and IVF outcome parameters. The clinical characteristics, biochemical and IVF outcome parameters of patients are presented in Table I. There were no significant differences between the two groups in the mean age, $\mathrm{BMI}$, duration of infertility, $\mathrm{E}_{2}$ concentration in the FF, as well as the serum levels of the $\mathrm{LH}, \mathrm{E}_{2}$ and $\mathrm{P}_{4}$ at the time of hCG administration ( $\mathrm{P}>0.05$; Table $\mathrm{I}$ ). However, the AOPP concentration in the FF was significantly higher in the EM group when compared with that in the control group $\left(\mathrm{P}<0.05\right.$; Fig. 1). In addition, the levels of $\mathrm{P}_{4}$ in the FF were significantly lower in the EM group as compared with the control group ( $\mathrm{P}<0.01$; Fig. 2). Regarding the outcome of IVF, the EM group presented reduced numbers of mature follicles (diameter of $>14 \mathrm{~mm}$ ), fertilizations and good embryos as compared with those in the control group $(\mathrm{P}<0.05$; Fig. 3$)$. Furthermore, the blastocyst rate was markedly lower in 


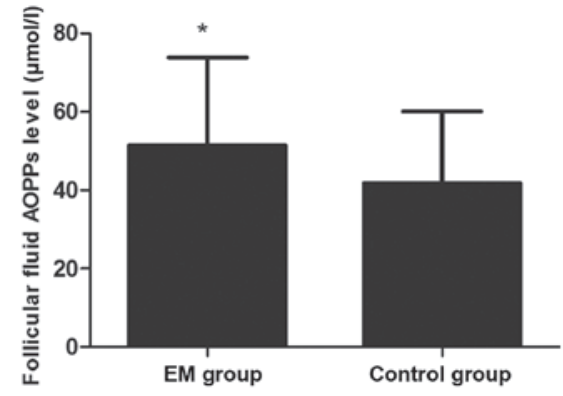

Figure 1. Mean level of follicular fluid AOPPs in the EM ( $n=44)$ and control $(n=45)$ groups. Values are presented as the mean \pm standard deviation. ${ }^{*} \mathrm{P}<0.05$ vs. the control group. AOPPs, advanced oxidation protein products; EM, endometriosis.

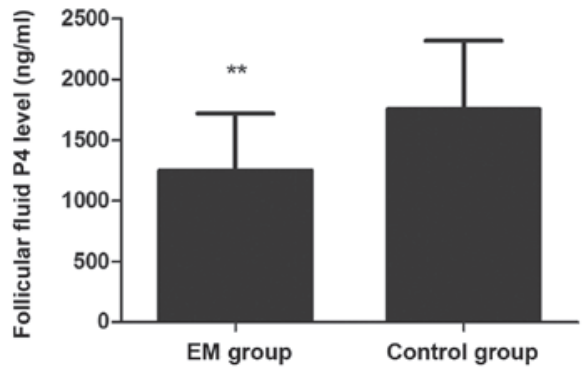

Figure 2. Mean $\mathrm{P}_{4}$ level in the follicular fluid in the $\mathrm{EM}(\mathrm{n}=44)$ and control $(n=45)$ groups. Values are presented as the mean \pm standard deviation. ${ }^{* *} \mathrm{P}<0.01$ vs. the control group. $\mathrm{P}_{4}$, progesterone; $\mathrm{EM}$, endometriosis.

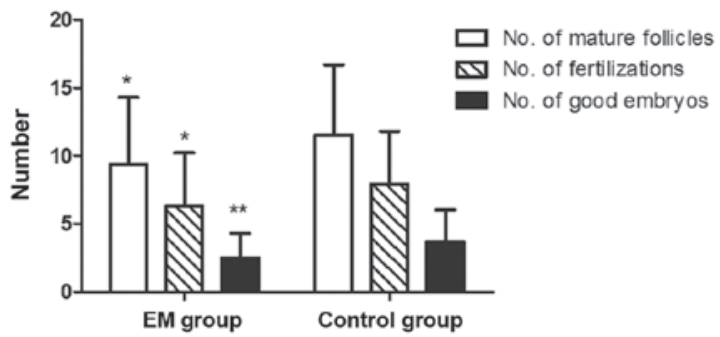

Figure 3. Mean number of mature follicles (with a diameter of $>14 \mathrm{~mm}$ ), fertilizations and good embryos in the EM $(n=44)$ and control $(n=45)$ groups. Values are presented as the mean \pm standard deviation. ${ }^{*} \mathrm{P}<0.05$ and ${ }^{* *} \mathrm{P}<0.01$, vs. the control group. EM, endometriosis.

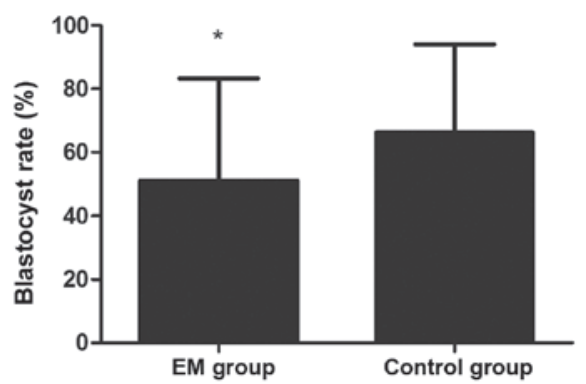

Figure 4. Mean blastocyst rate in the EM $(n=44)$ and control $(n=45)$ groups. Values are presented as the mean \pm standard deviation. ${ }^{*} \mathrm{P}<0.05$ vs. the control group. EM, endometriosis.

the EM group in comparison with that in the control group $(\mathrm{P}<0.05$; Fig. 4).
Correlation between FF AOPP concentration and hormone levels. The correlation between the AOPP concentration in the FF and the levels of gonadal hormones is demonstrated in Table II. The FF AOPP concentration exhibited a significant negative correlation with the level of $\mathrm{P}_{4}$ in the FF (EM group: $\mathrm{r}=-0.406, \mathrm{P}=0.006$; control group: $\mathrm{r}=-0.315, \mathrm{P}=0.035$; total: $\mathrm{r}=-0.421, \mathrm{P}<0.001)$. By contrast, no significant correlations were identified between the FF AOPP concentration and the serum levels of $\mathrm{LH}, \mathrm{E}_{2}$, and $\mathrm{P}_{4}$ at the time of $\mathrm{hCG}$ administration.

Correlation between AOPP concentration in the FF and the outcome parameters of IVF. Regarding the outcome of IVF, a negative correlation was observed between the FF AOPP concentration and the blastocyst rate in the EM and the total groups (EM group: $\mathrm{r}=-0.376, \mathrm{P}=0.012$; total: $\mathrm{r}=-0.367$, $\mathrm{P}<0.001$; Table III). However, no significant correlation was obsrved between the FF AOPP concentration and the fertilization rate, or between the FF AOPP concentration and the good embryos rate.

\section{Discussion}

EM has been demonstrated to be a disease closely associated with oxidative stress and the inflammatory reaction (33). AOPPs are the products of the oxidative stress reaction between chlorinated oxidants and plasma albumin $(32,34)$. In the peritoneal fluid and serum of patients with EM, the AOPP concentration was significantly increased $(21,35)$. To date, the AOPPs in the FF of patients with EM have not been widely investigated, although certain other oxidative stress markers have been reported. For instance, 8-hydroxy-2'-deoxyguanosine, ROS, nitric oxide and lipid peroxidation were all reportedly higher in the FF of EM patients when compared with the healthy individuals $(36,37)$. This suggests that there is more acute oxidative stress reaction in the FF of EM patients. In the present study, the AOPP level in the FF of infertile women with EM was markedly higher in comparison with the controls, which was in agreement with previous studies.

The quality of oocytes is a pivotal factor associated with the success rate of IVF. Oocyte maturation depends on the appropriate acquisition of cytoplasmic and nuclear maturation, with the latter depending on the presence of a normal cell spindle $(38,39)$. The microenvironment in FF is closely associated with the formation of spindles and the distribution of chromosome (40-42). Certain inflammatory factors in the FF, including tumor necrosis factor $\alpha$ and interleukin-17A, have also been reported to adversely affect oocytes $(43,44)$. The FF in EM patients may induce oxidative stress reaction in oocytes and cause DNA damage (45). In addition, AOPPs in the plasma induce endoplasmic reticulum stress in various cells (46-49), and this stress has been observed to cause phenotypic alterations and death in cells $(50,51)$. Under an environment with acute oxidative stress, the oocyte maturation is more likely to be arrested and the developmental potency of embryos is inevitably decreased. As observed in the current study, a reduced number of mature oocytes was retrieved and fertilized in the infertile patients with EM, and consequently, fewer good embryos could be used.

Another key factor for oocyte maturation is the gonadal hormone level, such as the level of $\mathrm{P}_{4}$. Although no correlation 
Table II. Correlations between the AOPP level in the FF and the gonadal hormone levels.

\begin{tabular}{|c|c|c|c|c|c|c|}
\hline \multirow[b]{3}{*}{ Measurements } & \multicolumn{6}{|c|}{ AOPP level } \\
\hline & \multicolumn{2}{|c|}{ EM group $(n=44)$} & \multicolumn{2}{|c|}{ Control group $(n=45)$} & \multicolumn{2}{|c|}{ Total $(n=89)$} \\
\hline & $\mathrm{r}$ & P-value & $\mathrm{r}$ & P-value & $\mathrm{r}$ & P-value \\
\hline \multicolumn{7}{|l|}{ FF content } \\
\hline $\mathrm{E}_{2}$ & -0.052 & 0.737 & -0.203 & 0.180 & -0.162 & 0.129 \\
\hline $\mathrm{P}_{4}$ & -0.406 & $0.006^{\mathrm{a}}$ & -0.315 & $0.035^{\mathrm{b}}$ & -0.421 & $<0.001^{\mathrm{a}}$ \\
\hline \multicolumn{7}{|l|}{$\begin{array}{l}\text { Prior to hCG } \\
\text { administration }\end{array}$} \\
\hline LH & 0.273 & 0.073 & 0.072 & 0.639 & 0.177 & 0.097 \\
\hline $\mathrm{E}_{2}$ & 0.130 & 0.399 & -0.141 & 0.355 & -0.046 & 0.668 \\
\hline $\mathrm{P}_{4}$ & -0.136 & 0.380 & -0.076 & 0.620 & -0.122 & 0.254 \\
\hline
\end{tabular}

${ }^{a} \mathrm{P}<0.01$ and ${ }^{\mathrm{b}} \mathrm{P}<0.05$. All analyses were performed using the Spearman's rank correlation test. EM, endometriosis; AOPP, advanced oxidation protein product; $\mathrm{FF}$, follicular fluid; $\mathrm{E}_{2}$, estradiol; $\mathrm{P}_{4}$, progesterone; $\mathrm{hCG}$, human chorionic gonadotropin; $\mathrm{LH}$, luteinizing hormone.

Table III. Correlations between the AOPP levels in the follicular fluid and the outcome parameters of in vitro fertilization.

\begin{tabular}{|c|c|c|c|c|c|c|}
\hline \multirow[b]{3}{*}{ Parameters } & \multicolumn{6}{|c|}{ AOPP level } \\
\hline & \multicolumn{2}{|c|}{ EM group $(n=44)$} & \multicolumn{2}{|c|}{ Control group $(n=45)$} & \multicolumn{2}{|c|}{ Total $(n=89)$} \\
\hline & $\mathrm{r}$ & $\mathrm{P}$-value & $\mathrm{r}$ & P-value & $\mathrm{r}$ & $\mathrm{P}$-value \\
\hline No. of follicles (diameter, >14 mm) & 0.066 & 0.670 & -0.052 & 0.736 & -0.055 & 0.609 \\
\hline No. of fertilizations & 0.082 & 0.598 & 0.027 & 0.862 & -0.019 & 0.862 \\
\hline Fertilization rate $(\%)$ & 0.093 & 0.547 & 0.107 & 0.483 & 0.028 & 0.797 \\
\hline No. of good embryos & 0.086 & 0.578 & -0.100 & 0.513 & -0.067 & 0.535 \\
\hline Good embryo rate $(\%)$ & 0.014 & 0.928 & -0.253 & 0.093 & -0.140 & 0.190 \\
\hline Blastocyst rate $(\%)$ & $-0.376^{\mathrm{a}}$ & 0.012 & -0.161 & 0.292 & $-0.367^{b}$ & $<0.001$ \\
\hline
\end{tabular}

${ }^{\mathrm{a}} \mathrm{P}<0.05$ and ${ }^{\mathrm{b}} \mathrm{P}<0.01$. All analyses were performed using the Spearman's rank correlation test. EM, endometriosis; AOPP, advanced oxidation protein product.

has been detected between the serum level of $\mathrm{P}_{4}$ and the prognosis of assisted reproductive technology (ART) (52), the $\mathrm{P}_{4}$ level in the FF only secreted and synthesized by granulosa cells is more closely correlated with the development of oocytes and the outcome of IVF $(53,54)$. In the present study, the EM group with a higher FF AOPP concentration presented a lower $\mathrm{FF}_{4}$ level, thus a negative correlation was observed between AOPPs and $\mathrm{P}_{4}$ levels. Santulli et al (21) and Gomes et al (55) reported that the peritoneal fluid of EM patients containing a higher level of AOPPs reduced the $\mathrm{P}_{4}$ release from granulosa cells. Therefore, the higher level of AOPPs in the FF of EM patients may be the cause of the decreased $\mathrm{P}_{4}$ level.

The negative influence of oxidative stress on granulosa cells is unimportant; oxdative stress causes mitochondrial and endoplasmic reticulum defects in granular cells and the generation of ROS in granulosa cells is accompanied with caspase 3/7 expression, an important indicator for cells apoptosis (56). Extreme oxidative stress is able to induce granulosa cell apoptosis (57); however, the antioxidant factor would exert a positive effect. L-DOPA in FF as an antioxidant factor that exerts positive influences on granular cells, including decreasing $\mathrm{H}_{2} \mathrm{O}_{2}$ production and promoting cell survival (58). Based on these observations, AOPPs may decrease $\mathrm{P}_{4}$ production via impairing the function of granulosa cells. In addition, in mammalian preovulatory follicles, $\mathrm{P}_{4}$ is one of the dominant steroid hormones (59). $\mathrm{P}_{4}$ regulates meiosis and ovulation by activating the progesterone receptors (60). A high level of $\mathrm{P}_{4}$ in the FF increases the percentage of oocytes at the germinal vesicle stage, and the maternal $\mathrm{P}_{4}$ level affects the gene transcripts of cumulus-oocyte complexes (54). By contrast, upon the lack of the necessary hormonal stimulation from $\mathrm{P}_{4}$, the development and maturation of oocytes would be delayed or may even not reach an acceptable level $(61,62)$.

The present study observed that the EM patients with fewer mature oocytes and fewer good-quality embryos presented a lower blastocyst rate. In the EM group and in the total cohort 
of patients, the correlation between AOPP concentration in the FF and blastocyst rate presented a significant negative correlation. The low success rate of ART may be explained by the low oocyte quality and blockage of embryo development (63). In clinical practice, selecting good-quality oocytes and embryos is key for promoting ART. Blastocysts represent a vital stage in the embryo development, and a good-quality blastocyst indicates a greater likelihood of implantation and gives rise to live birth (64-67). Oocytes, one of the origins of embryos, have been demonstrated to be associated with the developmental potential of the embryo; thus, good-quality oocytes are more likely to develop into blastocysts following fertilization $(68,69)$. As described previously, excessive oxidative stress in FF is inversely correlated with the prognosis of pregnancy in ART (70). Furthermore, oocytes with cytoplasmic defects are more likely to occur in an acute oxidative stress environment (71). While the elevated AOPPs may inhibit the appearance of the first polar body and cytoplasmic maturation, thus arresting oocyte maturation and damaging the potential of embryos (45), AOPPs may also damage the function of granulosa cells and decrease $\mathrm{P}_{4}$ production. Due to the lack of sufficient hormonal support of $\mathrm{P}_{4}$, oocyte maturation is arrested and the subsequent processes, including fertilization, blastocyst formation and embryo development, are negatively affected. This hypothesis is in accordance with previous experiments on rhesus monkeys, which reported that a higher ratio of $\mathrm{P}_{4}$ to $E_{2}$ in the FF was beneficial for the development of the embryos (72). In addition, this is consistent with the findings of Gustafson et al (73), suggesting that a higher $\mathrm{E}_{2} / \mathrm{P}_{4}$ ratio in the $\mathrm{FF}$ was associated with a lower IVF success rate. Therefore, an impairment of oocyte quality, lower implantation and reduced pregnancy rates are observed in patients with EM $(74,75)$.

However, the current study had various limitations. The major limitation is the overall small number of patients included. Furthermore, no significant correlations between the FF AOPP level and other gonadal hormones levels in the FF or serum were observed; however, this does not indicate that there are no correlations between the FF AOPP and other various gonadal hormones A larger sample size may provide more substantive evidence in further studies.

In conclusion, AOPP levels were significantly elevated in the FF of infertile patients with EM in the present study. In addition, the increased FF AOPP level was accompanied with a decreased $\mathrm{FF} \mathrm{P}_{4}$ concentration and blastocyst rate. These findings indicate that AOPP may be a potentially effective marker for predicting the oocyte quality and outcome of IVF, particularly in infertile women with EM. This provides a novel theoretical basis, suggesting that anti-oxidative treatments aimed at reducing the AOPP levels may be a new effective strategy to promote the maturation of oocytes and improve the success rate of IVF.

\section{Acknowledgements}

The authors would like to thank Dr. Wei Cao and Dr. Jianwei Tian (Department of Nephrology, Southern Medical University, Guangzhou, China) for their technical assistance. The present study was supported by the National Natural Science
Foundation of China (grant no. 81401180), the Population and Family Planning Commission Scientific Research Project of Guangdong Province in China (grant no. 20133058) and the Medical Scientific Research Foundation of Guangdong Province in China (grant no. A2013371).

\section{References}

1. Agarwal A, Gupta S, Abdel-Razek H, Krajcir N and Athayde K: Impact of oxidative stress on gametes and embryos in an ART Laboratory. Clin Embryol 9: 5-22, 2006.

2. Esfandiari N, Falcone T, Agarwal A, Attaran M, Nelson DR and Sharma RK: Protein supplementation and the incidence of apoptosis and oxidative stress in mouse embryos. Obstet Gynecol 105: 653-660, 2005

3. Liu XM, Zhang YP, Ji SY, Li BT, Tian X, Li D, Tong C and Fan HY: Mitoguardin-1 and -2 promote maturation and the developmental potential of mouse oocytes by maintaining mitochondrial dynamics and functions. Oncotarget 7: 1155-1167, 2016.

4. Zhang X, Wu XQ, Lu S, Guo YL and Ma X: Deficit of mitochondria-derived ATP during oxidative stress impairs mouse MII oocyte spindles. Cell Res 16: 841-850, 2006.

5. International Classification of Diseases 10th edition (ICD-10). World Human Organization. Accessed Apr 16, 2015.

6. D'Hooghe TM, Debrock S, Hill JA and Meuleman C: Endometriosis and subfertility: Is the relationship resolved? Semin Reprod Med 21: 243-254, 2003.

7. Bérubé S, Marcoux S, Langevin M and Maheux R: Fecundity of infertile women with minimal or mild endometriosis and women with unexplained infertility. The Canadian collaborative group on endometriosis. Fertil Steril 69: 1034-1041, 1998.

8. Pellicer A, Navarro J, Bosch E, Garrido N, Garcia-Velasco JA, Remohi J and Simón C: Endometrial quality in infertile women with endometriosis. Ann N Y Acad Sci 943: 122-130, 2001.

9. Mansour G, Sharma RK, Agarwal A and Falcone T: Endometriosisinduced alterations in mouse metaphase II oocyte microtubules and chromosomal alignment: A possible cause of infertility. Fertil Steril 94: 1894-1899, 2010.

10. Fadhlaoui A, Bouquet de la Jolinière J and Feki A: Endometriosis and infertility: How and when to treat? Front Surg 1: 24, 2014.

11. Lessey BA, Lebovic DI and Taylor RN: Eutopic endometrium in women with endometriosis: Ground zero for the study of implantation defects. Semin Reprod Med 31: 109-124, 2013.

12. Basile N, Nogales Mdel C, Bronet F, Florensa M, Riqueiros M, Rodrigo L, Garcia-Velasco J and Meseguer M: Increasing the probability of selecting chromosomally normal embryos by time-lapse morphokinetics analysis. Fertil Steril 101: 699-704, 2014.

13. Xu B, Guo N, Zhang XM, Shi W, Tong XH, Iqbal F and Liu YS: Oocyte quality is decreased in women with minimal or mild endometriosis. Sci Rep 5: 10779, 2015.

14. Goud PT, Goud AP, Joshi N, Puscheck E, Diamond MP and AbuSoud HM: Dynamics of nitric oxide, altered follicular microenvironment, and oocyte quality in women with endometriosis. Fertil Steril 102: 151-159, 2014

15. Prieto L, Quesada JF, Cambero O, Pacheco A, Pellicer A Codoceo R and Garcia-Velasco JA: Analysis of follicular fluid and serum markers of oxidative stress in women with infertility related to endometriosis. Fertil Steril 98: 126-130, 2012.

16. Singh AK, Chattopadhyay R, Chakravarty B and Chaudhury K: Markers of oxidative stress in follicular fluid of women with endometriosis and tubal infertility undergoing IVF. Reprod Toxicol 42: 116-124, 2013.

17. Da Broi MG, Malvezzi H, Paz CC, Ferriani RA and Navarro PA: Follicular fluid from infertile women with mild endometriosis may compromise the meiotic spindles of bovine metaphase II oocytes. Hum Reprod 29: 315-323, 2014.

18. Santanam N, Zoneraich N and Parthasarathy S: Myeloperoxidase as a potential target in women with endometriosis undergoing IVF. Reprod Sci 24: 619-626, 2017.

19. Colombo G, Clerici M, Giustarini D, Portinaro N, Badalamenti S, Rossi R, Milzani A and Dalle-Donne I: A central role for intermolecular dityrosine cross-linking of fibrinogen in high molecular weight advanced oxidation protein product (AOPP) formation. Biochim Biophys Acta 1850: 1-12, 2015. 
20. Witko-Sarsat V, Gausson V, Nguyen AT, Touam M, Drüeke T, Santangelo F and Descamps-Latscha B: AOPP-induced activation of human neutrophil and monocyte oxidative metabolism: A potential target for $\mathrm{N}$-acetylcysteine treatment in dialysis patients. Kidney Int 64: 82-91, 2003

21. Santulli P, Chouzenoux S, Fiorese M, Marcellin L, Lemarechal H, Millischer AE, Batteux F, Borderie D and Chapron C: Protein oxidative stress markers in peritoneal fluids of women with deep infiltrating endometriosis are increased. Hum Reprod 30: 49-60, 2015.

22. Li HY, Hou FF, Zhang X, Chen PY, Liu SX, Feng JX, Liu ZQ, Shan YX, Wang GB, Zhou ZM, et al: Advanced oxidation protein products accelerate renal fibrosis in a remnant kidney model. J Am Soc Nephrol 18: 528-538, 2007.

23. Liu SX, Hou FF, Guo ZJ, Nagai R, Zhang WR, Liu ZQ, Zhou ZM, Zhou M, Xie D, Wang GB and Zhang X: Advanced oxidation protein products accelerate atherosclerosis through promoting oxidative stress and inflammation. Arterioscler Thromb Vasc Biol 26: 1156-1162, 2006

24. Cao W, Xu J, Zhou ZM, Wang GB, Hou FF and Nie J: Advanced oxidation protein products activate intrarenal renin-angiotensin system via a CD36-mediated, redox-dependent pathway. Antioxid Redox Signal 18: 19-35, 2013.

25. Wu Q, Zhong ZM, Pan Y, Zeng JH, Zheng S, Zhu SY and Chen JT: Advanced oxidation protein products as a novel marker of oxidative stress in postmenopausal osteoporosis. Med Sci Monit 21: 2428-2432, 2015.

26. Moti M, Amini L, Mirhoseini Ardakani SS, Kamalzadeh S, Masoomikarimi $M$ and Jafarisani $M$ : Oxidative stress and anti-oxidant defense system in Iranian women with polycystic ovary syndrome. Iran J Reprod Med 13: 373-378, 2015.

27. Santulli P, Borghese B, Lemaréchal H,Leconte M, Millischer AE, Batteux F, Chapron C and Borderie D: Increased serum oxidative stress markers in women with uterine leiomyoma. PLoS One 8: e72069, 2013

28. Jana SK, K NB, Chattopadhyay R, Chakravarty B and Chaudhury K: Upper control limit of reactive oxygen species in follicular fluid beyond which viable embryo formation is not favorable. Reprod Toxicol 29: 447-451, 2010.

29. Song YL, Quan S, Tian JW, Li H, Chen SM and Xing FQ: Relationship between protein oxidation levels in the follicular fluid and the outcome parameters of in vitro fertilization-embryo transplantation. Nan Fang Yi Ke Da Xue Xue Bao 29: 160-163, 2009 (In Chinese)

30. World Health Organization: WHO Laboratory Manual for the Examination Human Semen and Sperm-cervical Mucus Interaction. 4th edition. Cambridge University Press, Oxford, UK, 2010.

31. Giorgi VS, Da Broi MG, Paz CC, Ferriani RA and Navarro PA: $\mathrm{N}$-acetyl-cysteine and l-carnitine prevent meiotic oocyte damage induced by follicular fluid from infertile women with mild endometriosis. Repro Sci 23: 342-351, 2016.

32. Witko-Sarsat V, Friedlander M, Capeillère-Blandin C, Nguyen-Khoa T, Nguyen AT, Zingraff J, Jungers $P$ and Descamps-Latscha B: Advanced oxidation protein products as a novel marker of oxidative stress in uremia. Kidney Int 49: 1304-1313, 1996.

33. Agarwal A, Aponte-Mellado A, Premkumar BJ, Shaman A and Gupta S: The effects of oxidative stress on female reproduction: A review. Reprod Biol Endocrinol 10: 49, 2012.

34. Witko-Sarsat V, Friedlander M, Nguyen Khoa T, Capeillère-Blandin C, Nguyen AT, Canteloup S, Dayer JM, Jungers P, Drüeke T and Descamps-Latscha B: Advanced oxidation protein products as novel mediators of inflammation and monocyte activation in chronic renal failure. J Immunol 161 2524-2532, 1998.

35. Jana SK, Dutta M, Joshi M, Srivastava S, Chakravarty B and Chaudhury K: $1 \mathrm{H}$ NMR based targeted metabolite profiling for understanding the complex relationship connecting oxidative stress with endometriosis. Biomed Resint 2013: 329058, 2013.

36. Da Broi MG, de Albuquerque FO, de Andrade AZ, Cardoso RL, Jordão Junior AA and Navarro PA: Increased concentration of 8-hydroxy-2'-deoxyguanosine in follicular fluid of infertile women with endometriosis. Cell Tissue Res 366: 231-242, 2016

37. Singh AK, Chattopadhyay R, Chakravarty B and Chaudhury K: Markers of oxidative stress in follicular fluid of women with endometriosis and tubal infertility undergoing IVF. Repro Toxicol 42: 116-124, 2013.
38. Mattson BA and Albertini DF: Oogenesis: Chromatin and microtubule dynamics during meiotic prophase. Mol Reprod Dev 25: 374-383, 1990

39. Albertini DF: Cytoplasmic microtubular dynamics and chromatin organization during mammalian oogenesis and oocyte maturation. Mutat Res 296: 57-68, 1992.

40. Ma CH, Yan LY, Qiao J, Sha W, Li L, Chen Y and Sun QY: Effects of tumor necrosis factor-alpha on porcine oocyte meiosis progression, spindle organization, and chromosome alignment. Fertil Steril 93: 920-926, 2010

41. Sabbaghi M, Aram R, Roustaei H, Fadavi Islam M, Daneshvar M, Castaño AR and Haghparast A: IL-17A concentration of seminal plasma and follicular fluid in infertile men and women with various clinical diagnoses. Immunol Invest 43: 617-626, 2014.

42. Pauli SA, Session DR, Shang W, Easley K, Wieser F, Taylor RN, Pierzchalski K, Napoli JL, Kane MA and Sidell N: Analysis of follicular fluid retinoids in women undergoing in vitro fertilization: Retinoic acid influences embryo quality and is reduced in women with endometriosis. Reprod Sci 20: $1116-1124,2013$

43. Opperman CM and Sishi BJ: Tumor necrosis factor alpha stimulates p62 accumulation and enhances proteasome activity independently of ROS. Cell Biol Toxicol 31: 83-94, 2015.

44. Żbikowska-Gotz M, Pałgan K, Gawrońska-Ukleja E, Kuźmiński A, Przybyszewski M, Socha E and Bartuzi Z: Expression of IL-17A concentration and effector functions of peripheral blood neutrophils in food allergy hypersensitivity patients. Int J Immunopathol Pharmacol 29: 90-98, 2016.

45. Hamdan M, Jones KT, Cheong Y and Lane SI: The sensitivity of the DNA damage checkpoint prevents oocyte maturation in endometriosis. Sci Rep 6: 36994, 2016.

46. Yuan F, Liu SX and Tian JW: Advanced oxidation protein products induce reactive oxygen species production in endothelial cells. Di Yi Jun Yi Da Xue Xue Bao 24: 1350-1352, 2004 (In Chinese).

47. Zhou QG, Zhou M, Lou AJ, Xie D and Hou FF: Advanced oxidation protein products induce inflammatory response and insulin resistance in cultured adipocytes via induction of endoplasmic reticulum stress. Cell Physiol Biochem 26: 775-786, 2010.

48. Rong G, Tang X, Guo T, Duan N, Wang Y, Yang L, Zhang J and Liang X: Advanced oxidation protein products induce apoptosis in podocytes through induction of endoplasmic reticulum stress. J Physiol Biochem 71: 455-470, 2015.

49. Liang X, Duan N, Wang Y, Shu S, Xiang X, Guo T, Yang L, Zhang S, Tang X and Zhang J: Advanced oxidation protein products induce endothelial-to-mesenchymal transition in human renal glomerular endothelial cells through induction of endoplasmic reticulum stress. J Diabetes Complications 30: 573-579, 2016

50. Bouvier N, Flinois JP, Gilleron J, Sauvage FL, Legendre C, Beaune P, Thervet E, Anglicheau D and Pallet N: Cyclosporine triggers endoplasmic reticulum stress in endothelial cells: A role for endothelial phenotypic changes and death. Am J Physiol Renal Physiol 296: F160-F169, 2009.

51. Zhang XY, Yang SM, Zhang HP, Yang Y, Sun SB, Chang JP, Tao XC, Yang TY, Liu C and Yang YM: Endoplasmic reticulum stress mediates the arsenic trioxide-induced apoptosis in human hepatocellular carcinoma cells. Int J Biochem Cell Biol 68: $158-165,2015$.

52. Timur H, Yimaz N, Kahyaoglu I, Inal HA and Erkaya S: The effect of serum and follicular fluid amyloid-associated protein levels on in vitro fertilization outcome in patients with polycystic ovary syndrome. J Assist Reprod Genet 32: 1637-1642, 2015.

53. Wen X, Li D, Tozer AJ, Docherty SM and Iles RK: Estradiol, progesterone, testosterone profiles in human follicular fluid and cultured granulosa cells from luteinized pre-ovulatory follicles. Reprod Biol Endocrinol 8: 117, 2010.

54. Bogacki M, Wasielak M, Kitewska A, Bogacka I and Jalali BM: The effect of hormonal estrus induction on maternal effect and apoptosis-related genes expression in porcine cumulus-oocyte complexes. Reprod Biol Endocrinol 12: 32, 2014.

55. Gomes FM, Navarro PA, de Abreu LG, Ferriani RA, dos Reis RM and de Moura MD: Effect of peritoneal fluid from patients with minimal/mild endometriosis on progesterone release by human granulosa-lutein cells obtained from infertile patients without endometriosis: A pilot study. Eur J Obstet Gynecol Reprod Biol 138: 60-65, 2008.

56. Bar-Joseph H, Ben-Ami I, Ron-El R, Shalgi R and Chuderland D: Pigment epithelium-derived factor exerts antioxidative effects in granulosa cells. Fertil Steril 102: 891-898.e3, 2014 
57. Saller S, Kunz L, Berg D, Berg U, Lara H, Urra J, Hecht S, Pavlik R, Thaler CJ and Mayerhofer A: Dopamine in human follicular fluid is associated with cellular uptake and metabolism-dependent generation of reactive oxygen species in granulosa cells: Implications for physiology and pathology. Hum Reprod 29: 555-567, 2014.

58. Blohberger J, Buck T, Berg D, Berg U, Kunz L and Mayerhofer A: L-DOPA in the hu man ovarian follicular fluid acts as an antioxidant factor on granulosa cells. J Ovarian Res 9: 62, 2016.

59. Su YQ, Sugiura K, Woo Y, Wigglesworth K, Kamdar S, Affourtit J and Eppig JJ: Selective degradation of transcripts during meiotic maturation of mouse oocytes. Dev Biol 302: 104-117, 2017.

60. Salehnia M and Zavareh S: The effects of progesterone on oocyte maturation and embryo development. Int J Fertil Steril 7: 74-81, 2013.

61. Bertoldo M, Holyoake PK, Evans G and Grupen CG: Oocyte developmental competence is reducedin sows during the seasonal infertility period. Reprod Fertil Dev 22: 1222-1229, 2010.

62. Grupen CG and Armstrong DT: Relationship between cumulus cell apoptosis, progesterone production and porcine oocyte developmental competence: Temporal effects of follicular fluid during IVM. Reprod Fertil Dev 22: 1100-1109, 2010.

63. Catala MG, Izquierdo D, Rodriguez-Prado M, Hammami S and Paramio MT: Effect of oocyte quality on blastocyst development after in vitro fertilization (IVF) and intracytoplasmic sperm injection (ICSI) in a sheep model. Fertil Steril 97: 1004-1008, 2012.

64. Braude P, Bolton V and Moore S: Human gene expression first occurs between the four- and eight-cell stages of preimplantation development. Nature 332: 459-461, 1988.

65. Lagalla C, Barberi M, Orlando G, Sciajno R, Bonu MA and Borini A: A quantitative approach to blastocyst quality evaluation: Morphometric analysis and related IVF outcomes. J Assist Reprod Genet 32: 705-712, 2015.

66. Dokras A, Sargent IL and Barlow DH: Human blastocyst grading: An indicator of developmental potential? Hum Reprod 8 2119-2127, 1993
67. De Kock A, Smuts MP, Madden JD, Rodriguez AJ, Chantilis SJ and Meintjes M: Digital image analysis of blastocysts. Morphometrics correlations with pregnancy outcome. Fertil Steril 86 (Suppl): S51-S52, 2006.

68. Van Blerkom J, Davis PW and Lee J: ATP content of human oocytes and developmental potential and outcome after in-vitro fertilization and embryo transfer. Hum Reprod 10: 415-424, 1995.

69. Stojkovic M, Machado SA, Stojkovic P, Zakhartchenko V, Hutzler P, Goncalves PB and Wolf E: Mitochondrial distribution and adenosine triphosphate content of bovine oocytes before and after in vitro maturation: Correlation with morphological criteria and developmental capacity after in vitro fertilization and culture. Biol Reprod 64: 904-909, 2001.

70. Bedaiwy MA, Elnashar SA, Goldberg JM, Sharma R, Mascha EJ, Arrigain S, Agarwal A and Falcone T: Effect of follicular fluid oxidative stress parameters on intracytoplasmic sperm injection outcome. Gynecol Endocrinol 28: 51-55, 2012.

71. Van Blerkom J, Antczak M and Schrader R: The developmental potential of the human oocyte is related to the dissolved oxygen content of follicular fluid: Association with vascular endothelial growth factor levels and perifollicular blood flow characteristics. Hum Reprod 12: 1047-1055, 1997.

72. Morgan PM, Boatman DE and Bavister BD: Relationships between follicular fluid steroid hormone concentrations, oocyte maturity, in vitro fertilization and embryonic development in the rhesus monkey. Mol Reprod Dev 27: 145-151, 1990.

73. Gustafson O, Nylund L and Carlström K: Does hyperandrogenism explain lower in vitro fertilization (IVF) success rates in smokers? Acta Obstet Gynecol Scand 75: 149-156, 1996.

74. Kuivasaari P, Hippelainen M, Anttila M and Heinonen S: Effect of endometriosis on IVF/ICSI outcome: Stage III/IV endometriosis worsens cumulative pregnancy and live-born rates. Hum Reprod 20: 3130-3135, 2005.

75. Jancar N, Kopitar AN, Ihan A, Virant KI and Bokal EV: Effect of apoptosis and reactive oxygen species production in human granulosa cells on oocyte fertilization and blastocyst development. J Assist Reprod Genet 24: 91-97, 2007. 